Bekkers, M.B.M, Koppes, L.L.J., Rodenburg, W., Steeg, H. van, Proper, K.I. Relationship of nighth and shift work with weight change and lifestyle behaviors. Journal of Occupational and

\begin{tabular}{|l|l|}
$\begin{array}{l}\text { Postprint } \\
\text { Version }\end{array}$ & 1.0 \\
\hline Journal website & $\frac{\text { http://journals.Iww.com/joem/Abstract/2015/04000/The Relationship Between O }}{\text { ccupational Metal.2.aspx }}$ \\
\hline Pubmed link & $\underline{\text { http://www.ncbi.nlm.nih.gov/pubmed/25749131 }}$ \\
\hline DOI & $10.1097 /$ JOM.0000000000000427 \\
\hline
\end{tabular}

This is a NIVEL certified Post Print, more info at http://www.nivel.eu

\title{
Relationship of Night and Shift Work With Weight Change and Lifestyle Behaviors
}

\author{
BekKers, Marga B. M. PhD; Koppes, Lando L. J. PhD; Rodenburg, Wendy PhD; Van \\ STEEG, HARRY PHD; PROPER, KARIN I. PHD \\ From the Centre for Nutrition, Prevention and Health Services (Drs Bekkers and Proper), \\ National Institute for Public Health and the Environment (RIVM), Bilthoven; NIVEL (Dr \\ Koppes), Netherlands Institute for Health Services Research, Utrecht; TNO (Dr Koppes), \\ Division Work and Employment, Hoofddorp; Centre for Health Protection (Drs Rodenburg \\ and van Steeg), National Institute for Public Health and the Environment (RIVM), Bilthoven; \\ and Department of Public and Occupational Health (Dr Proper), the EMGO+ Institute for \\ Health and Care Research, VU University Medical Center, Amsterdam, the Netherlands. \\ This work has been commissioned by the Dutch Ministry of Social Affairs and Employment. \\ The authors declare no conflicts of interest.
}

\begin{abstract}
Objective: To prospectively study the association of night and shift work with weight change and lifestyle behaviors.

Methods: Workers participating in the Netherlands Working Conditions Cohort Study (2008 and 2009) $(\mathrm{N}=5951)$ reported night and shift work, weight and height. Groups included stable night or shift work, from day work to night or shift work, from night or shift work to day work, and no night or shift work in 2008 and 2009. Regression analyses were used to study association changes in night and shift work with weight change and changes in lifestyle behaviors.

Results: A larger weight change was seen in normal-weight workers changing from day to shift work ([beta] $=0.93 \% ; 95 \%$ confidence interval, 0.01 to 1.85 ) compared with stable no shift workers. No further associations of night and shift work with weight change were observed, neither in normal-weight, overweight, and obese workers.

Conclusions: Despite the fact that starting night or shift work is associated with some unhealthy lifestyle habits, this study did not confirm a positive association of night and shift work with weight change over 1 year, except for normalweight workers moving from day to shift work.
\end{abstract}

The evolved 24/7 economy, due to increasing economic and social demands, resulted in an increasing number of jobs including evening and night shifts or irregular working hours.1 About one in five workers in Europe are thought to be exposed to 
shift work including night work. ${ }^{1,2}$ In the Netherlands, $17 \%$ of the employed nivel population report to work in shifts sometimes or regularly, whereas $52 \%$ of the employees report to work sometimes or regularly during the evening or night. ${ }^{3}$ Adverse health effects have been reported in shift workers and are receiving increased attention. Shift work including night work has been associated with several types of cancer, cardiovascular, and gastrointestinal diseases. ${ }^{2,4,5}$ The causal mechanisms linking shift work to health conditions are not well defined yet, but they seem to be multifactorial and include among others disruption of the circadian rhythm, metabolic disturbances, and changed lifestyle habits. ${ }^{2}$ For example, shift or night workers smoke more and more often have unhealthy eating habits and patterns, as well as lack of physical activity compared with day workers. ${ }^{6,7}$ Two recent reviews on the health effects of shift work concluded that shift work is likely to be associated with negative health outcomes, but that the studies performed so far have heterogeneous designs and not all are of good quality. ${ }^{5,8}$ More specifically, van Drongelen et al ${ }^{8}$ reviewed the evidence on shift work in relation to weight gain. They concluded strong evidence for a crude association between shift work exposure and body weight increase; however, the evidence for a confounder-adjusted relationship between shift work exposure and body weight gain was considered insufficient. Therefore, the authors stated that more and better quality studies are necessary. On the basis of the effects of shift/night work on energy balance-related behaviors, it is however plausible that weight gain will occur, making people working in shifts at increased risk of developing overweight or obesity. A body mass index (BMI) increase was observed in shift work maintainers. ${ }^{9}$ Overweight and obesity are a growing health problem, with increasing costs because of overweightrelated diseases, but also by productivity loss and disability costs. ${ }^{10}$ The overweight prevalence in the Netherlands increased to around 40\% among women and 50\% in men in 2012. ${ }^{11}$ This is in line with the increasing overweight prevalence worldwide. ${ }^{12}$ Estimates of the increased health care costs because of obesity range from $2 \%$ to $7 \%$ of the total health care costs in Western countries. ${ }^{13}$ As overweight is associated with adverse health effects and higher productivity loss (eg, due to higher sick leave rates 9) thereby contributing to large direct and indirect costs, it is important to get more insight into the effects of night and shift work with weight gain. Moreover, overweight and obesity are proposed pathways, linking shift work to cancer and cardiovascular diseases. ${ }^{8,14}$ As the association of night and shift work with weight change, controlled for confounders, is not clear yet, we aim to prospectively study the association of night and shift work with weight change in a large cohort of Dutch employees. In addition, to get more insight into the behavioral patterns of night and shift work, we examined the association of changes in work schedules (from night and shift work to day work, or the reverse) with changes in lifestyle behaviors.

\section{METHODS}

\section{Study Population}

Data of the Netherlands Working Conditions Cohort Study over the years 2008 and 2009 were used. ${ }^{15,16}$ The Netherlands Working Conditions Cohort Study is currently the largest prospective longitudinal study on the quality of work and working conditions available in the Netherlands. Employees aged 15 to 64 years are included, 
Bekkers, M.B.M, Koppes, L.L.J., Rodenburg, W., Steeg, H. van, Proper, K.I. Relationship of nighth and shift work with weight change and lifestyle behaviors. Journal of Occupational and

whereas self-employed individuals are excluded. In 2007, 80,000 individuals were sampled from the Dutch working population database of Statistics Netherlands. This database contains information on all jobs, which fall under employee national insurance schemes, and are liable to income tax. Sampling was random, except for a $50 \%$ oversampling of employees younger than 23 years and of employees with a nonwestern background, because the response rate in these two groups was known to be relatively low. Individuals in the sample received the written questionnaire by mail at their home address in the first week of November 2007. The questionnaire could be filled out with a pencil or via the Internet using a personal code that was printed on the questionnaire. In total, questionnaires of $32.8 \%$ of the employed sampled individuals were available for analysis in $2007(\mathrm{n}=22,759)$ of the total sample derived from the Dutch working population database of Statistics Netherlands (Fig. 1). In November 2008, 19,161 people who had provided consent to be contacted in future received the first follow-up questionnaire of the Netherlands Working Conditions Cohort Study. In total, 10,393 of the 19,161 people (54\%) who responded to the first questionnaire also answered the second questionnaire. In 2009, 7028 of the 9,207 people with complete data on weight, height, shift, and night work in 2008 responded to the second follow-up questionnaire. After exclusion of respondents with missing data on shift or night work (most because they were no longer employed), weight or height and work status in 2009, outliers (standard deviation [SD], >3) with regard to height and weight change, and women with suspected pregnancy, the final study sample consisted of 5951 people.

\section{[FIGURE 1]}

\section{Shift Work and Night Work}

Employees filled out a questionnaire at baseline and after 12 and 24 months, in 2007, 2008 , and 2009, respectively. Workers were asked to report their weekly working hours according to their contract and whether they had a fixed-term or permanent contract. Full-time employment was defined as at least 36 hours per week according to the contract. Working during the evening or at night (here called "night work") in the past year and shift work were asked using single questions with answer categories on a three-point scale (never, sometimes, and regularly). The exact questions were: "In the past year, have you worked in the evening or night?" and for shift work: "Do you work in shifts?"

\section{Body Weight and Height}

Weight and height were asked in the follow-up questionnaires only. Weight change was calculated as the difference in kilogram between 2009 and 2008, and as percentage difference of body weight in 2008. A positive difference reflects weight gain, and a negative difference reflects weight loss. The BMI was calculated as weight $/$ height ${ }^{2}\left(\mathrm{~kg} / \mathrm{m}^{2}\right)$. Weight categories were created as follows: underweight $<18$ $\mathrm{kg} / \mathrm{m}^{2}$; normal weight 18 to $24.9 \mathrm{~kg} / \mathrm{m}^{2}$; overweight 25 to $29.9 \mathrm{~kg} / \mathrm{m}^{2}$; and obesity $>=30 \mathrm{~kg} / \mathrm{m}^{2} .{ }^{17}$ Because of the small number of underweight people in this cohort, three categories were applied in this article with the people classified "underweight" in the normal-weight category. 
Bekkers, M.B.M, Koppes, L.L.J., Rodenburg, W., Steeg, H. van, Proper, K.I. Relationship of nighth and shift work with weight change and lifestyle behaviors. Journal of Occupational and

\section{Lifestyle Behaviors}

In the follow-up questionnaires (2008 and 2009), questions on lifestyle habits were included. The number of days with physical activity for at least 30 minutes during leisure time and work together, and during work only was reported. In our analyses we divided subjects into two categories for both variables: 5 days a week or more physical active for at least 30 minutes, and less than 5 days a week physical active. Alcohol consumption was asked by a single question to the usual number of drinks per week. Smoking behavior was assessed with a question to the number of cigarettes per week. We dichotomized the variables alcohol consumption and smoking behavior into yes and no (0 cigarette a week). Last, respondents were asked about their usual breakfast behavior on working days (never, sometimes, often, and always).

\section{Covariates}

Respondents were asked to their sex and year of birth. The highest educational level attained was asked on an eight-point scale and subsequently categorized into low (primary school, lower and intermediate secondary schooling, or lower vocational training), intermediate (higher secondary schooling or intermediate vocational training), and high (higher vocational training or university). Respondents were also asked to indicate whether they had a partner and whether their partner had a paid job. Physical workload was assessed with a single question on pushing, pulling, or using force, with answers on a three-point scale (no, sometimes, and regularly). ${ }^{15,16}$ Questions on job demands (four items) were based on the Job Content Questionnaire, with answers on a four-point scale, ranging from never to always ${ }^{18}$ (ie, Do you have to work very fast? Do you have a lot of work? Do you have to slog away? Is your job hectic?). Three questions on emotional demands of the job (no, sometimes, and regularly) were asked, derived from the Copenhagen Psychosocial Questionnaire 19 (ie, Does your job get you into emotionally difficult situations? Is your job emotionally demanding? Are you emotionally involved at work?). Sum scores of the scales job demands and emotionally demanding work were dichotomized on the basis of the median value of the sample because of the skewed distribution of some variables. Employees also indicated whether they had a chronic disease. As the weight change from 2008 to 2009 was studied, "baseline" characteristics were from the 2008 measurement.

\section{ANALYSIS}

To study the association of night and shift work with weight change between 2008 and 2009, linear regression analyses were used. In the questionnaire of 2007, no questions on lifestyle and body weight were included, and thus could not be used for this study.

Subjects were assigned to one of the four night work categories and to one of the four shift work categories. The categories were as follows: stable night or shift work (2008 and 2009); change from day work to night or shift work (only 2009); change from night or shift work to day work (only 2008); and no night or shift work in both years (reference group). A potential confounder was included in the regression analyses if it changed the association between the exposure and outcome measures 
Bekkers, M.B.M, Koppes, L.L.J., Rodenburg, W., Steeg, H. van, Proper, K.I. Relationship of nighth and shift work with weight change and lifestyle behaviors. Journal of Occupational and

more than $10 \%$. The following variables were checked for confounding: sex, age, smoking, alcohol consumption, physical activity at home, physical activity at work, physical workload, education, chronic disease, emotional demands, job demands, ethnicity, and temporary contract. Two models were used to study the association of shift and night work with weight change. The first model was a crude model; the second model included sex, age, educational level, and physical work load that seemed to be confounders. The analyses were performed for the total study group and separately for the normal-weight, overweight, and obese workers. In addition, logistic regression was performed to study the association between change in night or shift work from 2008 to 2009 and change in lifestyle habits (ie, breakfast, physical activity, alcohol consumption, and smoking). For all the analyses conducted in this study, SAS software version 9.3 (SAS Institute, Inc, Cary, NC) was used.

\section{RESULTS}

In 2008, 2996 respondents (50\%) reported to work during the night, occasionally, or regularly. More men than women reported to work during the night $(54 \%$ and $46 \%$, respectively). In the group of night workers in 2008, intermediate (39\%) and high (49\%) education were more frequent compared with the group of employees with no night work $(\mathrm{P}<0.05)$ (Table 1). Mean weight was $77 \mathrm{~kg}(\mathrm{SD}, 14.3 \mathrm{~kg})$ in the group that did not work during the night and $78 \mathrm{~kg}(\mathrm{SD}, 14.5 \mathrm{~kg})$ that did work during the night in 2008. The weight change from 2008 to 2009 varied around $0.5 \mathrm{~kg}$ and $0.6 \%$ in the total study group. In those who did not perform night work, the weight change was $0.3 \mathrm{~kg}(\mathrm{SD}, 3.2 \mathrm{~kg})$ and $0.5 \mathrm{~kg}(\mathrm{SD}, 3.0 \mathrm{~kg})$ in stable night workers (Table 2). In the group of stable night and shift workers, $76.9 \%$ and $72.7 \%$, respectively, had always breakfast on working days, and $23.0 \%$ and $27.7 \%$, respectively, were smokers (Tables 2 and 3). About one third (29\% to 37\%) was physically active on 5 days of the week for at least 30 minutes per day in leisure time and at work.

\section{[TABLE 1][TABLE 2][TABLE 3]}

\section{Association Between Night Work and Weight Change}

In both 2008 and 2009, 2459 workers (41\%) reported working during the night. Night work (either in both years or only in 2008 or 2009) was not significantly associated with weight change (Table 4). Stratification by BMI status showed no significant associations between night work and weight change (Table 5).

\section{[TABLE 4][TABLE 5]}

\section{Association Between Shift Work and Weight Change}

In both 2008 and 2009, 649 workers (11\%) reported to work in shifts. No associations between shift work and weight change were observed in the total group (Table 4). Analyses of the association between shift work and weight change stratified by BMI status showed that normal-weight workers changing from day to shift work experienced larger weight change ([beta $]=0.93 \% ; 95 \%$ confidence interval [CI], 0.01 to 1.85 ) compared with those not working in shifts (Table 5). In 
Bekkers, M.B.M, Koppes, L.L.J., Rodenburg, W., Steeg, H. van, Proper, K.I. Relationship of night and shift work with weight change and lifestyle behaviors. Journal of Occupational and

the groups of workers with overweight or obesity, no associations between shift work and weight change were observed.

\section{Association Between Changes in Night Work and Lifestyle Behaviors}

A significant association was seen in alcohol nonconsumers moving from night to day work with alcohol consumption in that they were less likely to start drinking (odds ratio [OR], $0.46 ; 95 \%$ CI, 0.23 to 0.91 ) than those not working during the night (Table 6). In addition, alcohol consumers moving from day to night work increased their alcohol consumption from 2008 to 2009 compared with workers not working during the night (OR, 1.29; 95\% CI, 1.06 to 1.58). No significant associations were observed for changes in work schedule with changes in breakfast, physical activity during leisure time and work, and smoking.

\section{[table 6]}

\section{Association Between Changes in Shift Work and Lifestyle Behaviors}

With regard to lifestyle habits, workers moving from shift to day work more frequently increased their physical activity during leisure time compared with stable no-shift workers (OR, 1.37; 95\% CI, 0.96 to 1.95) (Table 6). More frequently than stable no-shift workers, the shift to day work movers changed their breakfast behavior (from yes to no: OR, 2.08; $95 \%$ CI, 1.25 to 3.46; and from no to yes: OR, $2.09 ; 95 \%$ CI, 1.31 to 3.34 ). No associations were observed with alcohol consumption and smoking. On the other hand, those who moved from day work to shift work adopted unhealthier lifestyle habits in that nonsmokers more frequently started smoking (OR, 3.00; 95\% CI, 1.28 to 7.05 ).

\section{DISCUSSION}

We found a significant increased body weight over a 1-year period in normal-weight workers who moved from day work to shift work. No further associations were however found to support the hypothesis that people working during nights or in shifts over a period are at increased risk of gaining extra weight compared with people only working daytimes. Despite previous research to the effects of night and shift work on weight-related outcomes, the evidence is currently insufficient with heterogeneity between the few high-quality studies as important reason. 8 For example, a prospective study that monitored workers starting a new job showed a decrease over 1 year in BMI in shift workers compared with day workers. 20 The same authors also investigated the effect of the duration of shift work on weightrelated outcomes and found a positive relationship between years worked in shifts with BMI.21 In addition, a recent prospective study suggested that shift work could increase BMI over a 2-year period.9 Their data showed a BMI decrease in shift to day changers, and increases in BMI in shift work maintainers and those who changed from day to shift work.9 Like in our study, shift work also included working in the evenings and night. Unfortunately, they did not study night work separately. In this study, the night work definition includes working during the evenings, suggesting that night workers in this study did not all experience disruption of the circadian system, possibly explaining that we did not observe an association between night work and weight change. One factor likely to play a role in the association between 
Bekkers, M.B.M, Koppes, L.L.J., Rodenburg, W., Steeg, H. van, Proper, K.I. Relationship of nighth and shift work with weight change and lifestyle behaviors. Journal of Occupational and Environmental Medicine: 2015, 57(4), e37-e44

night work and weight change is disruption of the circadian system. Circadian misalignment causes disturbance of metabolic hormones such as insulin, cortisol, and satiety hormones.22-24 We hypothesize that the disturbance is larger in those working during the night than in those working during the evenings. As mentioned before, the causal mechanisms linking night work to health conditions are not completely understood yet. Future research to night work and weight change, with several shift work patterns using objective data, may be relevant. Our results on shift work suggesting weight change are supported by the findings of the review of van Drongelen et al 8 that investigated shift work including nightshifts in relation to weight change. Taking these studies together, they showed a crude association between shift work including night shifts, but this association was no longer present after adjustment for confounders. Other factors, such as dietary habits and physical activity, are likely to play an important role. Total energy intake does not change substantially, but workers on night shifts eat on different times and are likely to consume more high-energy snacks. 6 The association of night work with weight change was based on the hypothesis that behavior is a mediator in this association. We observed differences in lifestyle characteristics between the night or shift workers and day workers with night or shift workers having more components of an unhealthy lifestyle. In addition, we studied whether a change in night or shift work was associated with changes in lifestyle behaviors. On the basis of the results, it can be concluded that starting night or shift work was associated with the adoption of some unhealthy lifestyle habits, such as starting drinking and smoking, whereas moving from night or shift work to day coincided with stopping alcohol consumption and an increase in physical activity. These observed differences in lifestyle behaviors are mostly in line with the hypothesized behavioral mechanism in the effect of night and shift work with weight gain. Nevertheless, because we did not find significant associations of night and shift work with weight change, these unhealthy lifestyle behaviors did not lead to weight change in our study sample. Other mechanisms may counteract the unhealthy lifestyle habits. For example, respondents working during the night in 2008 and 2009 are more frequently active on at least 5 days a week for more than 30 minutes a day during their working hours. This corresponds to the observation that night-shift workers experience more physical workload than workers with day shifts. Although we did not observe an association between night work and weight change, previous studies suggested adverse health effects of working during the night.2,4,5 Most of these studies are heterogeneous in design (ie, retrospective, case control, and prospective), and exposure and outcome measures. Heterogeneous also are the conclusions drawn in four recent meta-analyses on the link between night work and breast cancer, as summarized by Koppes et al.25 If that link exists, our study indicates that a more frequent use of alcohol among night workers may add to this relationship, as alcohol consumption is a known risk factor for breast cancer.26 Long-term changes in health and the behavioral pathway in this would be of interest for future research.

\section{Strengths and Limitations}

In the interpretation of this study finding, some methodological issues need to be considered. A major strength of this study is that data were from a large cohort study in the Netherlands, with information on a large variety of covariates. Because of its large sample, objective measurements were however not feasible. The use of self- 
Bekkers, M.B.M, Koppes, L.L.J., Rodenburg, W., Steeg, H. van, Proper, K.I. Relationship of night and shift work with weight change and lifestyle behaviors. Journal of Occupational and

reports could have led to bias. For example, some misclassification may have niver occurred because of underreporting of weight, especially in overweight and obese subjects. 27 Nevertheless, we do not expect differences in (under)reporting between the work status groups and between reporting in both years, and thereby assume the impact on the results only minimal. With respect to the measurement of shift and night work, it should be considered that single-item questions were used without detailed information about the shift types, night and shift work history, or the start of a new job. Such information is preferred to better establish effects of night or shift work and the duration of these work types on body weight. Although previous research has found significant weight changes in body weight between day and shift workers after 1 year,20 effects on body weight may take a certain time lag, implying that the study period of 1 year might have been too short to detect significant changes. This study however aimed to examine the effect on body weight as well as on important precursors, namely lifestyle behaviors, of which effects within a year may be expected. Moreover, the use of self-reported weight data, over a 1-year time frame, may explain the lack of significant changes in body weight. Another aspect that needs to be highlighted is the final sample size considering the initial study population. Main reasons for the decrease in total number were the response rate at follow-up (54\%) and missing data on the relevant variables. More than 500 respondents had to be excluded from the study population because of missing data on night or shift work. Comparison of baseline characteristics of respondents with and without information on night and shift work showed more women, lower educated employees, and more frequent alcohol consumption and smoking in the group of respondents that did not answer the questions on night and shift work in 2008 or 2009. Nevertheless, as we have still a large sample size of 5951 workers divided into the night and shift worker groups, the power of the analyses is large.

\section{CONCLUSIONS}

This study did not confirm an association of night and shift work with weight change over 1 year, except for normal-weight workers moving from day to shift work. Some changes in lifestyle behaviors were associated with changes in night or shift work that apparently did not lead to the assumed weight gain. Future studies into the effects and behavioral mechanisms using objective data and more detailed night and shift work data over a longer time frame are needed to get insight into the health risk of night and shift work.

\section{REFERENCES}

1. European Foundation for the Improvement of Living and Working Conditions. Working Conditions in the European Union: Working Time and Work Intensity. Luxembourg: Office for Official Publications of the European Communities; 2009.

2. Harrington JM. Health effects of shift work and extended hours of work. Occup Environ Med. 2001;58:68-72.

3. Koppes LLJ, de Vroome EMM, Mars GMJ, Janssen BJM, van Zwieten MHJ, van den Bossche SNJ. Nationale Enquete Arbeidsomstandigheden 2012: Methodologie 
Bekkers, M.B.M, Koppes, L.L.J., Rodenburg, W., Steeg, H. van, Proper, K.I. Relationship of nighth and shift work with weight change and lifestyle behaviors. Journal of Occupational and Environmental Medicine: 2015, 57(4), e37-e44

en Globale Resultaten [The Netherlands Working Conditions Survey 2012: Methodology and Overall Results]. Hoofddorp: TNO; 2013.

4. Kolstad HA. Nightshift work and risk of breast cancer and other cancers - a critical review of the epidemiologic evidence. Scand J Work Environ Health. 2008;34:5-22.

5. Wang XS, Armstrong ME, Cairns BJ, Key TJ, Travis RC. Shift work and chronic disease: the epidemiological evidence. Occup Med (Lond). 2011;61:78-89.

6. Atkinson G, Fullick S, Grindey C, Maclaren D. Exercise, energy balance and the shift worker. Sports Med. 2008;38:671-685.

7. Puttonen S, Harma M, Hublin C. Shift work and cardiovascular diseasepathways from circadian stress to morbidity. Scand J Work Environ Health. 2010;36:96-108.

8. van Drongelen A, Boot CR, Merkus SL, Smid T, van der Beek AJ. The effects of shift work on body weight change - a systematic review of longitudinal studies. Scand J Work Environ Health. 2011;37:263-275.

9. Zhao I, Bogossian F, Turner C. Does maintaining or changing shift types affect BMI? A longitudinal study. J Occup Environ Med. 2012;54:525-531.

10. van Duijvenbode DC, Hoozemans MJ, van Poppel MN, Proper KI. The relationship between overweight and obesity, and sick leave: a systematic review. Int J Obes (Lond). 2009;33:807-816.

11. CBS Pols. Permanent Onderzoek van de Leefomgeving. Gezondheid en Welzijn, CBS; 2012.

12. Finucane MM, Stevens GA, Cowan MJ, et al. National, regional, and global trends in body-mass index since 1980: systematic analysis of health examination surveys and epidemiological studies with 960 country-years and 9.1 million participants. Lancet. 2011;377:557-567.

13. Thompson D, Wolf AM. The medical-care cost burden of obesity. Obes Rev. 2001;2:189-197.

14. Fritschi L, Glass DC, Heyworth JS, et al. Hypotheses for mechanisms linking shiftwork and cancer. Med Hypotheses. 2011;77:430-436. Bibliographic Links

15. Van den Bossche SNJ, Koppes LLJ, Granzier JJH, De Vroome EMM, Smulders PGW. Nationale Enquête Arbeidsomstandigheden 2007: Methodologie en Globale Resultaten [The Netherlands Working Conditions Survey 2007: Methodology and Overall Results]. Hoofddorp: TNO; 2008. 
Bekkers, M.B.M, Koppes, L.L.J., Rodenburg, W., Steeg, H. van, Proper, K.I. Relationship of night and shift work with weight change and lifestyle behaviors. Journal of Occupational and Environmental Medicine: 2015, 57(4), e37-e44

16. Koppes LLJ, de Vroome EMM, van den Bossche SNJ. NEA Cohort Onderzoek 2007-2009: Methoden en Eerste Resultaten [The Netherlands Working Conditions Cohort Study 2007-2009: Methods and First Results]. Hoofddorp: TNO; 2011.

17. World Health Organization. Obesity and Overweight. Geneva, Switzerland: World Health Organization; 2013.

18. Karasek R, Brisson C, Kawakami N, Houtman I, Bongers P, Amick B. The Job Content Questionnaire (JCQ): an instrument for internationally comparative assessments of psychosocial job characteristics. J Occup Health Psychol. 1998;3:322-55.

19. Kristensen TS. Copenhagen Psychological Questionnaire. Stockholm, Sweden: National Institute for Working Life; 2001.

20. Van Amelsfoort LG, Schouten EG, Kok FJ. Impact of one year of shift work on cardiovascular disease risk factors. J Occup Environ Med. 2004;46:699-706.

21. Van Amelsfoort LG, Schouten EG, Kok FJ. Duration of shiftwork related to body mass index and waist hip ratio. Int J Obes Relat Metab Disord. 1999;23:973-978.

22. Gonnissen HK, Rutters F, Mazuy C, Martens EA, Adam TC, WesterterpPlantenga MS. Effect of a phase advance and phase delay of the 24-h cycle on energy metabolism, appetite, and related hormones. Am J Clin Nutr. 2012;96:689697.

23. Morris CJ, Fullick S, Gregson W, et al. Paradoxical post-exercise responses of acylated ghrelin and leptin during a simulated night shift. Chronobiol Int. 2010;27:590-605

24. Scheer FA, Hilton MF, Mantzoros CS, Shea SA. Adverse metabolic and cardiovascular consequences of circadian misalignment. Proc Nat Acad Sci USA. 2009; 106:4453-4458.

25. Koppes LLJ, Geuskens GA, Pronk A, Vermeulen RCH, de Vroome EMM. Night work and breast cancer risk in a general population prospective cohort study in the Netherlands. Eur J Epidemiol. 2014;29:577-584.

26. Bagnardi V, Tora M, Botteri E, et al. Alcohol consumption and site-specific cancer risk: a comprehensive dose-response meta-analysis. Br J Cancer. 2015;112:580-593.

27. Visscher TL, Viet AL, Kroesbergen HT, Seidell JC. Underreporting of BMI in adults and its effect on obesity prevalence estimations in the period 1998 to 2001 . Obesity. 2006;14:2054-2063. 
Bekkers, M.B.M, Koppes, L.L.J., Rodenburg, W., Steeg, H. van, Proper, K.I. Relationship of night and shift work with weight change and lifestyle behaviors. Journal of Occupational and Environmental Medicine: 2015, 57(4), e37-e44

\section{FIGURE, TABLES}

FIGURE 1. Flow chart.

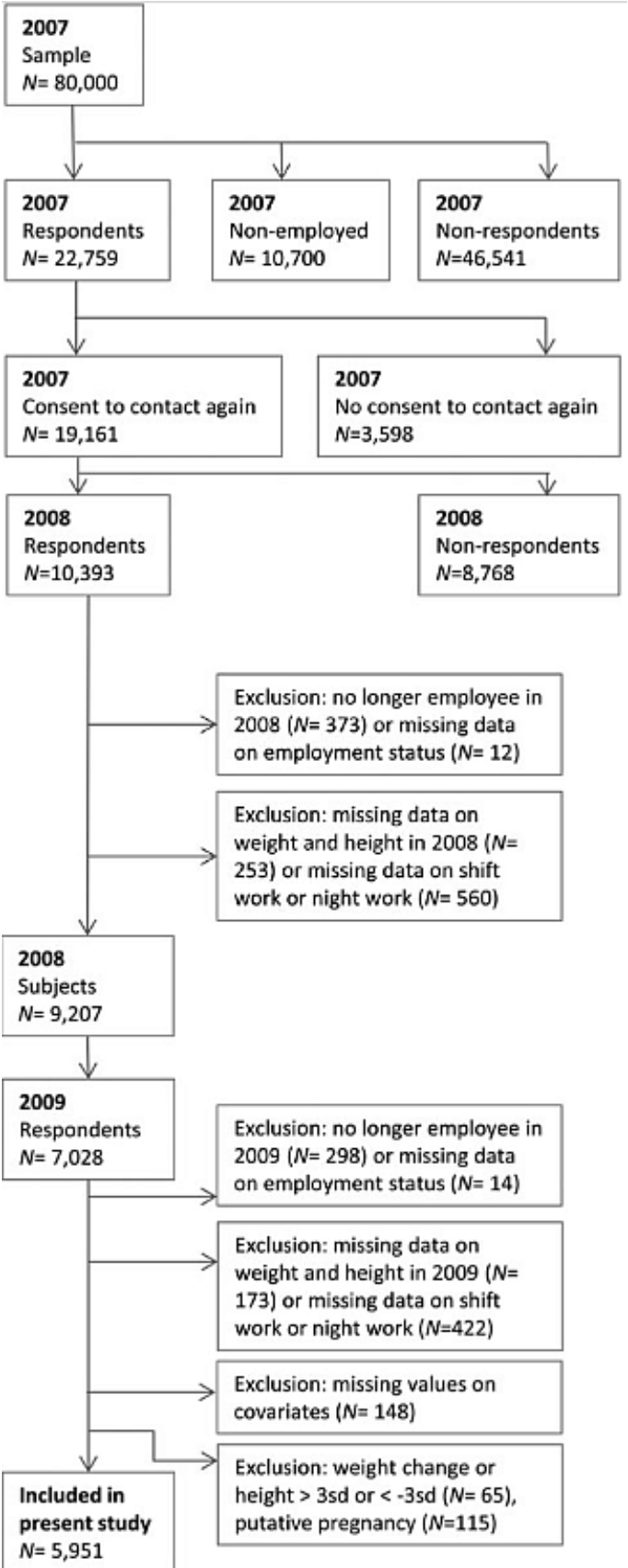


Bekkers, M.B.M, Koppes, L.L.J., Rodenburg, W., Steeg, H. van, Proper, K.I. Relationship of night and shift work with weight change and lifestyle behaviors. Journal of Occupational and Environmental Medicine: 2015, 57(4), e37-e44

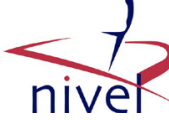

TABLE 1. Characteristics of the Study Sample in $2008(\mathrm{~N}=5951)$

\begin{tabular}{|c|c|c|c|c|}
\hline & $\begin{array}{c}\text { Night Work } \\
\text { (2008) } N=2996 \\
\%\end{array}$ & $\begin{array}{c}\text { No Night Work } \\
\text { (2008) } N=2955 \\
\%\end{array}$ & $\begin{array}{c}\text { Shift Work } \\
(2008) N=781 \\
\%\end{array}$ & $\begin{array}{c}\text { No Shift Work } \\
(2008) N=5170 \\
\%\end{array}$ \\
\hline Sex, male & $54.0^{*}$ & 45.1 & $43.5^{*}$ & 50.6 \\
\hline Dutch ethnicity & 91.7 & 91.1 & 91.0 & 91.5 \\
\hline \multicolumn{5}{|l|}{ Education } \\
\hline Low & $12.7^{*}$ & 20.3 & $21.4^{*}$ & 15.7 \\
\hline Intermediate & 38.7 & 36.6 & $55.8 *$ & 34.9 \\
\hline High & $48.7^{*}$ & 43.1 & $22.8^{*}$ & 49.4 \\
\hline \multicolumn{5}{|l|}{ Partner } \\
\hline Partner with paid job & 70.0 & 70.1 & $66.7 *$ & 70.5 \\
\hline Partner with no paid job & 12.1 & 13.5 & 10.3 & 13.2 \\
\hline No partner & 17.9 & 16.4 & 23.1 & 16.3 \\
\hline Chronic disease (yes) & $38.6^{*}$ & 41.5 & 38.5 & 40.2 \\
\hline Physical workload (sometimes or regularly) & $38.5^{*}$ & 24.6 & $70.3^{*}$ & 25.8 \\
\hline Shift work (sometimes or regularly) & $24.5^{*}$ & 1.6 & & \\
\hline \multirow[t]{2}{*}{ Night work (sometimes or regularly) } & & & $94.0^{*}$ & 43.8 \\
\hline & Median (IQR) & Median (IQR) & Median (IQR) & Median (IQR) \\
\hline Age, yrs & $44.0(18.0)$ & $47.0(17.0)$ & $44.0(18.0)$ & $46.0(17.0)$ \\
\hline Job demands & $2.3(0.8)$ & $2.3(0.5)$ & $2.3(0.8)$ & $2.3(0.8)$ \\
\hline Emotional job demands & $2.0(1.0)$ & $1.7(1.0)$ & $2.0(0.7)$ & $2.0(0.7)$ \\
\hline
\end{tabular}

TABLE 2. Lifestyle Characteristics in 2008 by Night Work Categories

\begin{tabular}{|c|c|c|c|c|}
\hline & $\begin{array}{l}\text { Stable Night } \\
\text { Work } \\
N=2459 \\
\text { Mean (SD) }\end{array}$ & $\begin{array}{c}\text { From Night Work } \\
\text { to Day Work } \\
N=\mathbf{5 3 1} \\
\text { Mean (SD) }\end{array}$ & $\begin{array}{c}\text { From Day Work } \\
\text { to Night Work } \\
N=551 \\
\text { Mean (SD) }\end{array}$ & $\begin{array}{c}\text { Stable No } \\
\text { Night Work } \\
N=2410 \\
\text { Mean (SD) }\end{array}$ \\
\hline Weight, kg & $78(14.3)$ & $78(13.6)$ & $77(14.3)$ & $76(13.9)$ \\
\hline \multirow[t]{2}{*}{ Weight change, $\mathrm{kg}$} & $0.5(3.0)$ & $0.2(3.2)$ & $0.6(3.0)$ & $0.3(3.2)$ \\
\hline & $\%$ & $\%$ & $\%$ & $\%$ \\
\hline \multicolumn{5}{|l|}{ BMI category } \\
\hline Underweight & 1.3 & 1.5 & 0.9 & 1.6 \\
\hline Normal weight & 56.2 & 53.8 & 58.3 & 53.0 \\
\hline Overweight & 33.3 & 36.7 & 33.0 & 35.9 \\
\hline Obesity & 9.2 & 8.0 & 7.8 & 9.5 \\
\hline Breakfast on working days, always* & 76.9 & 80.0 & 80.2 & 82.0 \\
\hline Alcohol consumption, yes* & 79.0 & 79.8 & 77.8 & 74.2 \\
\hline Smoking, yes* & 23.0 & 23.0 & 16.8 & 18.0 \\
\hline \multicolumn{5}{|l|}{ PA leisure and work } \\
\hline $5 \mathrm{~d},>30 \mathrm{~min} / \mathrm{d}$ & 31.2 & 30.3 & 30.0 & 29.3 \\
\hline \multicolumn{5}{|l|}{ PA work } \\
\hline $5 \mathrm{~d},>30 \mathrm{~min} / \mathrm{d}$ & 21.3 & 18.7 & 18.8 & 20.0 \\
\hline
\end{tabular}


Bekkers, M.B.M, Koppes, L.L.J., Rodenburg, W., Steeg, H. van, Proper, K.I. Relationship of night and shift work with weight change and lifestyle behaviors. Journal of Occupational and Environmental Medicine: 2015, 57(4), e37-e44

TABLE 3. Lifestyle Characteristics in 2008 by Shift work Categories

\begin{tabular}{|c|c|c|c|c|}
\hline & $\begin{array}{c}\text { Stable } \\
\text { Shift Work } \\
N=649 \\
\text { Mean (SD) }\end{array}$ & $\begin{array}{c}\text { From Shift Work } \\
\text { to Day Work } \\
N=132 \\
\text { Mean (SD) }\end{array}$ & $\begin{array}{c}\text { From Day Work } \\
\text { to Shift Work } \\
N=\mathbf{1 3 6} \\
\text { Mean (SD) }\end{array}$ & $\begin{array}{c}\text { Stable No } \\
\text { No Shift Work } \\
N=\mathbf{5 0 3 4} \\
\text { Mean (SD) }\end{array}$ \\
\hline Weight, kg & $77.0(14.7)$ & $77(15.1)$ & $77.5(14.5)$ & $77.3(14.0)$ \\
\hline \multirow[t]{2}{*}{ Weight change, $\mathrm{kg}$} & $0.6(3.3)$ & $0.3(3.7)$ & $0.6(3.6)$ & $0.4(3.0)$ \\
\hline & $\%$ & $\%$ & $\%$ & $\%$ \\
\hline \multicolumn{5}{|l|}{ BMI category } \\
\hline Underweight & 2.0 & 1.5 & 2.2 & 1.3 \\
\hline Normal weight & 53.5 & 57.6 & 48.5 & 55.2 \\
\hline Overweight & 35.1 & 31.1 & 36.8 & 34.6 \\
\hline Obesity & 9.4 & 9.9 & 12.5 & 83.1 \\
\hline Breakfast on working days, always* & 72.7 & 67.2 & 75.4 & 80.9 \\
\hline Alcohol consumption, yes & 75.4 & 77.1 & 77.2 & 77.3 \\
\hline Smoking, yes* & 27.7 & 24.4 & 22.6 & 19.4 \\
\hline \multicolumn{5}{|l|}{ PA leisure and work } \\
\hline $5 \mathrm{~d},>30 \mathrm{~min} / \mathrm{d}$ & 31.7 & 37.4 & 33.3 & 29.8 \\
\hline \multicolumn{5}{|l|}{ PA work* } \\
\hline $5 \mathrm{~d},>30 \mathrm{~min} / \mathrm{d}$ & 24.2 & 30.5 & 25.2 & 19.4 \\
\hline
\end{tabular}

TABLE 4. Association of Night and Shift work and Weight Change

\begin{tabular}{|c|c|c|c|}
\hline & $n$ & $\begin{array}{c}\text { Model 1* } \\
\beta(95 \% \text { CI) }\end{array}$ & $\begin{array}{c}\text { Model 2† } \\
\beta(95 \% \text { CI })\end{array}$ \\
\hline \multicolumn{4}{|l|}{ Night work } \\
\hline \multicolumn{4}{|l|}{ Weight change, $\mathrm{kg}$} \\
\hline Stable night work & 2459 & 0.12 (-0.05 to 0.29$)$ & $0.07(-0.11$ to 0.25$)$ \\
\hline From night work to day work & 537 & -0.17 ( -0.46 to 0.12$)$ & $-0.17(-0.46$ to 0.12$)$ \\
\hline From day work to night work & 551 & 0.25 ( -0.04 to 0.54$)$ & $0.26(-0.03$ to 0.55$)$ \\
\hline Stable no night work & 2404 & Reference & Reference \\
\hline \multicolumn{4}{|l|}{ Weight change, $\%$} \\
\hline Stable night work & 2459 & $0.13(-0.10$ to 0.35$)$ & $0.06(-0.17$ to 0.29$)$ \\
\hline From night work to day work & 537 & $-0.21(-0.58$ to 0.16$)$ & $-0.21(-0.58$ to 0.17$)$ \\
\hline From day work to night work & 551 & 0.31 ( -0.06 to 0.68$)$ & $0.32(-0.05$ to 0.69$)$ \\
\hline Stable no night work & 2404 & Reference & Reference \\
\hline \multicolumn{4}{|l|}{ Shift work } \\
\hline \multicolumn{4}{|l|}{ Weight change, kg } \\
\hline Stable shift work & 649 & $0.18(-0.07$ to 0.44$)$ & $0.01(-0.25$ to 0.28$)$ \\
\hline From shift work to day work & 132 & $-0.02(-0.56$ to 0.51$)$ & $-0.19(-0.73$ to 0.35$)$ \\
\hline From day work to shift work & 136 & $0.26(-0.26$ to 0.79$)$ & $0.09(-0.44$ to 0.62$)$ \\
\hline Stable no shift work & 5035 & Reference & Reference \\
\hline \multicolumn{4}{|l|}{ Weight change, $\%$} \\
\hline Stable shift work & 649 & $0.24(-0.08$ to 0.57$)$ & $0.02(-0.33$ to 0.36$)$ \\
\hline From shift work to day work & 132 & $0.02(-0.66$ to 0.71$)$ & $-0.22(-0.91$ to 0.47$)$ \\
\hline From day work to shift work & 136 & $0.41(-0.27$ to 1.09$)$ & $0.17(-0.51$ to 0.86$)$ \\
\hline Stable no shift work & 5035 & Reference & Reference \\
\hline
\end{tabular}


Bekkers, M.B.M, Koppes, L.L.J., Rodenburg, W., Steeg, H. van, Proper, K.I. Relationship of night and shift work with weight change and lifestyle behaviors. Journal of Occupational and Environmental Medicine: 2015, 57(4), e37-e44

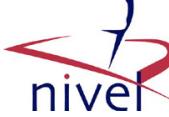

TABLE 5. Association Between Weight Change in Night and Shift work Groups According to BMI in 2008*

\begin{tabular}{|c|c|c|c|c|c|c|}
\hline & \multicolumn{2}{|c|}{$\begin{array}{c}\mathrm{BMI} \leq 25 \mathrm{~kg} / \mathrm{m}^{2} \\
N=3350\end{array}$} & \multicolumn{2}{|c|}{$\begin{array}{c}\text { BMI } 25-30 \mathrm{~kg} / \mathrm{m}^{2} \\
N=2062\end{array}$} & \multicolumn{2}{|c|}{$\begin{array}{c}\mathrm{BMI} \geq 30 \mathrm{~kg} / \mathrm{m}^{2} \\
N=539\end{array}$} \\
\hline & $n$ & $\beta(95 \% \mathrm{CI})$ & $n$ & $\beta(95 \% \mathrm{CI})$ & $n$ & $\beta(95 \% \mathrm{CI})$ \\
\hline \multicolumn{7}{|l|}{ Night work } \\
\hline \multicolumn{7}{|l|}{ Weight change, kg } \\
\hline Stable night work & 1415 & $0.03(-0.17$ to 0.23$)$ & 819 & $0.17(-0.16$ to 0.50$)$ & 225 & $0.06(-0.83$ to 0.95$)$ \\
\hline From night work to day work & 297 & $0.03(-0.30$ to 0.36$)$ & 197 & $-0.45(-0.97$ to 0.07$)$ & 43 & $0.08(-1.44$ to 1.60$)$ \\
\hline From day work to night work & 326 & $0.17(-0.15$ to 0.49$)$ & 182 & $0.33(-0.21$ to 0.86$)$ & 43 & 0.66 ( -0.87 to 2.19$)$ \\
\hline \multicolumn{7}{|l|}{ Weight change, $\%$} \\
\hline Stable night work & 1415 & $0.02(-0.28$ to 0.32$)$ & 819 & $0.19(-0.21$ to 0.58$)$ & 225 & $-0.03(-0.91$ to 0.86$)$ \\
\hline From night work to day work & 297 & $0.02(-0.46$ to 0.51$)$ & 197 & $-0.51(-1.13$ to 0.12$)$ & 43 & $0.02(-1.50$ to 1.54$)$ \\
\hline From day work to night work & 326 & $0.22(-0.24$ to 0.69$)$ & 182 & $0.42(-0.22$ to 1.06$)$ & 43 & $0.64(-0.88$ to 2.16$)$ \\
\hline \multicolumn{7}{|l|}{ Shift work } \\
\hline \multicolumn{7}{|l|}{ Weight change, $\mathrm{kg}$} \\
\hline Stable shift work & 360 & $-0.06(-0.36$ to 0.25$)$ & 228 & $0.14(-0.34$ to 0.62$)$ & 61 & $-0.01(-1.30$ to 1.27$)$ \\
\hline From shift work to day work & 78 & $-0.06(-0.65$ to 0.53$)$ & 41 & $-0.58(-1.62$ to 0.46$)$ & 13 & 0.03 ( -2.56 to 2.62$)$ \\
\hline From day work to shift work & 69 & $0.61(-0.02$ to 1.23$)$ & 50 & $-0.22(-1.16$ to 0.72$)$ & 17 & $-0.89(-3.18$ to 1.40$)$ \\
\hline \multicolumn{7}{|l|}{ Weight change, $\%$} \\
\hline Stable shift work & 360 & $-0.06(-0.51$ to 0.38$)$ & 228 & $0.17(-0.41$ to 0.75$)$ & 61 & $-0.06(-1.34$ to 1.21$)$ \\
\hline From shift work to day work & 78 & $-0.03(-0.90$ to 0.83$)$ & 41 & $-0.76(-2.01$ to 0.49$)$ & 13 & 0.04 ( -2.54 to 2.62$)$ \\
\hline From day work to shift work & 69 & $0.93(0.01$ to 1.85$) \dagger$ & 50 & $-0.43(-1.57$ to 0.71$)$ & 17 & $-0.73(-3.01$ to 1.55$)$ \\
\hline $\begin{array}{l}\text { *Adjusted for sex, age, education, at } \\
\text { analyses of shift work. } \\
\text { †Significant associations are represe } \\
\text { BMI, body mass index; CI, confiden }\end{array}$ & $\begin{array}{l}\text { sical n } \\
\text { italic } \\
\text { erval. }\end{array}$ & & & & & \\
\hline
\end{tabular}

TABLE 6. Association Between Night and Shift work and Lifestyle Behaviors*

\begin{tabular}{|c|c|c|c|c|}
\hline & \multicolumn{2}{|c|}{ Night Work } & \multicolumn{2}{|c|}{ Shift Work } \\
\hline & $\begin{array}{c}\text { From Night Work } \\
\text { to Day Work } \\
\text { OR }(95 \% \text { CI })\end{array}$ & $\begin{array}{c}\text { From Day Work } \\
\text { to Night Work } \\
\text { OR }(95 \% \text { CI })\end{array}$ & $\begin{array}{c}\text { From Shift Work } \\
\text { to Day Work } \\
\text { OR }(95 \% \mathrm{CI})\end{array}$ & $\begin{array}{c}\text { From Day Work } \\
\text { to Shift Work } \\
\text { OR }(95 \% \text { CI })\end{array}$ \\
\hline \multicolumn{5}{|l|}{ Breakfast } \\
\hline Decrease in breakfast frequency & $1.14(0.79-1.65)$ & $1.37(0.97-1.93)$ & $2.08(1.25-3.46) \dagger$ & $0.72(0.33-1.54)$ \\
\hline Increase in breakfast frequency & $1.27(0.93-0.17)$ & $1.17(0.85-1.60)$ & $2.09(1.31-3.34)$ & $1.50(0.89-2.51)$ \\
\hline \multicolumn{5}{|l|}{ Alcohol consumption } \\
\hline Decrease in alcohol consumption & $1.05(0.86-1.28)$ & $1.05(0.86-1.28)$ & $1.05(0.73-1.52)$ & $1.15(0.81-1.64)$ \\
\hline Increase in alcohol consumption & $0.89(0.72-1.10)$ & $1.29(1.06-1.58)$ & $1.01(0.69-1.48)$ & $0.83(0.56-1.23)$ \\
\hline Starting alcohol consumption & $0.46(0.23-0.91)$ & $1.20(0.75-1.90)$ & $0.96(0.35-2.62)$ & $0.94(0.34-2.58)$ \\
\hline Quitting alcohol consumption & $0.89(0.50-1.56)$ & $0.56(0.29-1.09)$ & $1.02(0.37-2.79)$ & $1.26(0.51-3.13)$ \\
\hline \multicolumn{5}{|l|}{ Smoking } \\
\hline Starting smoking & $0.60(0.26-1.43)$ & $1.21(0.63-2.31)$ & $1.00(0.24-4.13)$ & $3.00(1.28-4.13)$ \\
\hline Quitting smoking & $1.25(0.70-2.24)$ & $0.56(0.25-1.25)$ & $0.38(0.05-2.74)$ & $1.50(0.54-4.15)$ \\
\hline \multicolumn{5}{|l|}{ Physical activity } \\
\hline Decrease in physical activity & $1.13(0.93-1.38)$ & $1.08(0.89-1.32)$ & $1.07(0.74-1.56)$ & $1.30(0.91-1.85)$ \\
\hline Increase in physical activity & $0.96(0.79-1.18)$ & $0.98(0.81-1.20)$ & $1.37(0.96-1.95)$ & $1.18(0.83-1.69)$ \\
\hline
\end{tabular}

